\title{
Função social da propriedade ou especulação imobiliária? A aplicação dos instrumentos de ordenamento territorial no município de São Paulo entre 2014 e 2019
}

\section{Social function of property or property speculation? Application of territorial ordering instruments in São Paulo city between 2014 and 2019}

\author{
José Diego Gobbo Alves $\sqrt{-10}$
}

Núcleo de Estudos e Pesquisas Ambientais (NEPAM), Universidade Estadual de Campinas, Campinas, São Paulo, Brasil

Recebido (Received): 10/11/2019

*E-mail para correspondência: jdgobboalves@gmail.com

\begin{abstract}
Resumo: Partindo da atuação dos diferentes agentes que produzem o espaço urbano, o propósito do artigo é analisar a aplicação dos instrumentos de gestão urbana no município de São Paulo, especificamente, o Parcelamento, Edificação ou Utilização Compulsórios (PEUC) e o Imposto sobre a Propriedade Predial e Territorial Urbana (IPTU) progressivo no período de 2014 e 2019. Para a realização do objetivo, foi elaborado um mapeamento da distribuição das notificações de imóveis considerados ociosos pela prefeitura, bem como uma revisão bibliográfica sobre o processo de especulação recente no município, visando subsidiar os resultados encontrados no mapeamento temático. Foram encontradas 1.425 notificações realizadas pelo poder público municipal à proprietários de lotes que no entender do poder público não cumpriam a função social da propriedade. Os territórios administrativos das prefeituras regionais da Sé, Mooca e Ipiranga, respectivamente, foram os que concentraram maior número de notificações. A hipótese resultante deste estudo é a de que, no período analisado, a aplicação dos instrumentos de ordenamento territorial no município contribuiu para o cumprimento da função social da propriedade e da cidade e, contraditoriamente, tendeu a estimular a atuação do capital imobiliário em áreas de recente atratividade de capital. Este artigo contribui para as discussões acerca das relações entre o poder público municipal e o capital imobiliário, principalmente, no que tange aos nexos territoriais que conectam e expressam as intencionalidades dos agentes produtores do espaço urbano.
\end{abstract}

Palavras-Chaves: Especulação imobiliária; Função social; IPTU; PEUC; São Paulo.

Abstract: Starting from the performance of the different agents that produce the urban space, the article's purpose is to analyze the application of urban management instruments in São Paulo city, specifically, the Parcelamento, Edificação ou Utilização Compulsórios (PEUC) and the Imposto sobre a Propriedade Predial e Territorial Urbana (IPTU) between 2014 and 2019. To achieve the objective, a mapping of the distribution of notifications of properties considered idle by the City Hall was made, as well as a bibliographical review on the recent speculation process in the municipality was carried out, aiming to subsidize the results found in the thematic mapping. There were 1.425 notifications made by the municipal government to landowners who, according to public authorities, did not fulfill the social function of property. The administrative territories of the regional prefectures of Sé, Mooca and Ipiranga, respectively, were the ones that concentrated the largest number of notifications. The hypothesis resulting from the study is that, in the analyzed period, the application of spatial planning instruments in the municipality contributed to the fulfillment of the social function of property and, contradictorily, tended to stimulate the action of capital property in areas of recent capital attractiveness. This article contributes to the discussions about the relations between the public government and the capital property, especially with regard to the connecting territorial links and express the intentionalities of the agents producing urban space.

Keywords: Property speculation; Social function; IPTU; PEUC; São Paulo. 


\section{Introdução}

$\mathrm{O}$ modo como as cidades vêm sendo produzidas totalmente à mercê aos interesses privados dos agentes hegemônicos (CORRÊA, 1989; SPOSITO, 2011), aliado com o crescente enclausuramento no espaço privado como um modo de vida contemporâneo (LIMONAD, 2007; OJIMA; MARANDOLA JUNIOR, 2016), tem tornado as cidades dispersas e fragmentadas, negando a convivência com o diferente, e segregando os grupos sociais em um processo que se retroalimenta e se mantém (SOUZA, 2013). A dinâmica de apropriação do espaço pelo capital, como uma forma de resolução da crise de sobreacumulação já descrito por Harvey (2005), pode ser observada nas cidades brasileiras por meio da expansão do mercado imobiliário (COUTO, 2015) que transformou as cidades em um grande canteiro de obras (ROLNIK; KLINK 2011).

Nos últimos anos, a especulação imobiliária de terras urbanas ganhou um impulso com a expansão do mercado imobiliário que age de forma predatória em relação ao espaço. A especulação é um dos principais problemas encontrados nas cidades atualmente, sendo danosa para todo o conjunto social ao aumentar o preço do solo urbano e diminuir o número de moradias disponíveis, acarretando processos como o de segregação espacial e gentrificação (SANTOS, 1989; VILLAÇA, 1986). A gênese da especulação imobiliária nas cidades brasileiras, varia de acordo com a própria história de ocupação territorial, o que demanda estudos locais aprofundados para apreender a complexidade e as especificidades da especulação em cada contexto.

A literatura aponta o papel do Estado como um dos principais agentes responsáveis pela produção do espaço urbano em diversas escalas (CORRÊA, 1989), bem como, as implicações que esse processo gerou e vem gerando para as cidades brasileiras. A visão de que o Estado, por meio da gestão e das políticas públicas, busca atacar um problema real que beneficiaria a sociedade como um todo é uma visão simplista (SERAFIM; DIAS, 2012), que mascara toda a intencionalidade e as contradições inerentes ao poder público, que o impulsiona para beneficiar determinados grupos específicos. Essa afirmação é importante para problematizar a visão positiva de que a política pública possui para o conjunto social, ou seja, de que toda a política pública traz apenas resultados positivos. Assim, deve-se apreender a política pública como o Estado em movimento (SERAFIM; DIAS, 2012), sendo um movimento que perpassa toda a sua estrutura material e imaterial por meio de ações (e não-ações) em prol de um objetivo pré-estabelecido, elaborado a partir de intencionalidades de grupos da sociedade.

No município de São Paulo, a articulação Estado-capital está inserida em uma trama complexa de agentes que estão articulados em diferentes escalas espaciais, viabilizando a relação entre o mercado financeiro e o território, criando um complexo Imobiliário-Financeiro (PEREIRA et al., 2018). Essa articulação tem reestruturado a cidade para viabilizar a reprodução do capital imobiliário, de forma que as operações urbanas de revitalização em diversos pontos da cidade, pautam-se nas demandas do mercado imobiliário e não nas demandas das populações residentes dessas áreas (VITOR et al., 2018).

A regulamentação pelo Estatuto da Cidade (BRASIL, 2001) dos instrumentos de gestão urbana propostos na Constituição Federal de 1988, o Estatuto da Metrópole (BRASIL, 2015) e a Política Nacional de Mobilidade Urbana (BRASIL, 2012) são políticas urbanas importantes que retira do âmbito estritamente municipal a problemática urbana, ao criar em nível nacional parâmetros de ordenamento territorial e estabelecer, pelo menos no nível retórico, a articulação entre os entes federativos. Fruto de longo processo de disputa, as políticas urbanas apresentam-se como a possibilidade de transformação dos espaços vividos (MARICATO, 2015).

Nesse contexto, o propósito do artigo é discutir a importância da aplicação de instrumentos de ordenamento territorial que coíbem a especulação imobiliária e como eles estão sendo utilizados no município de São Paulo, especificamente, o Parcelamento, Edificação ou Utilização Compulsórios (PEUC) e o Imposto sobre a Propriedade Predial e Territorial Urbana (IPTU) progressivo no período de 2014 e 2019. A hipótese resultante deste estudo é a de que, no período analisado, a aplicação dos instrumentos de ordenamento territorial no município contribuiu para o cumprimento da função social da propriedade e da cidade e, contraditoriamente, tendeu a estimular a atuação do capital imobiliário em áreas de recente atratividade de capital.

A metodologia do artigo consistiu em análise dos dados disponibilizados pela prefeitura do município de São Paulo sobre a aplicação dos instrumentos urbanísticos de gestão urbanas relacionado à função social da propriedade e levantamento e análise da bibliografia que versa sobre os processos de especulação imobiliária no município. Para o mapeamento, foi utilizado o software ArcGis, versão 10.4, onde foi elaborado um Sistema de Informação Geográfica (SIG), contendo a compilação dos dados quantitativos sobre os 
instrumentos de gestão aplicados pela gestão municipal, com base nas prefeituras regionais do município e a suas respectivas áreas em formato shapefile, realizando assim a espacialização dos dados.

\section{Instrumentos de ordenamento territorial e a função social da propriedade}

Os instrumentos de ordenamento territorial são um conjunto de leis das quais os governos locais se apoiam para gerir o território, servindo de base para a realização de intervenções urbanas. São vários os instrumentos na política urbana capazes de dar suporte para a tomada de decisão pelo poder público municipal e estes estão explícitos, no caso brasileiro, na Constituição Federal de 1988 (BRASIL, 1988) e regulamentados no Estatuto da Cidade de 2001 (BRASIL, 2001).

Os principais instrumentos de gestão urbana mencionados no Estatuto da Cidade (2001), relevantes para o tocante do artigo, são o próprio Estatuto como norteador de políticas públicas urbanas, os Planos Diretores municipais que trazem um diagnóstico local e os parâmetro legais de intervenção e os instrumentos da política urbana como o Parcelamento Edificação ou Utilização Compulsórios (PEUC), IPTU Progressivo no tempo, Desapropriação com pagamentos de títulos da dívida pública. Outros instrumentos que auxiliam no ordenamento territorial são as leis do parcelamento do solo e de Zoneamento urbano e rural; o Usucapião Especial de imóvel urbano, Concessão de uso para fins de moradia e a Transferência do Direito de Construir. A aplicabilidade desses instrumentos pode ser encontrada de forma detalhada no Estatuto da Cidade (2001).

De acordo com Schiffer (2006), a partir da década de 1990 tem-se uma maior fragmentação da política urbana em nível nacional que está atrelada com as medidas neoliberais aqui aplicadas. A partir da Constituição de 1988, os municípios passaram a ter a mesma igualdade jurídica que a União, o que lhes transferiram recursos e poder de decisão. Essa descentralização do poder, baseado no discurso de um planejamento mais democrático e próximo dos problemas urbanos específicos de cada município acarretou, segundo a autora, em uma descaracterização das políticas públicas urbanas em âmbito nacional, das quais a autora defende que sejam as únicas possíveis soluções dos problemas estruturais da sociedade brasileira, tais como

[...] a desigualdade inter-regiões, a distribuição de renda, o acesso à terra, financiamentos para população de baixa-renda para aquisição de bens e moradia, etc. Em outras palavras, instituía-se a fragmentação das políticas urbanas, ocultada justamente pela disseminação de mecanismos de "participação popular" e descentralização administrativa. (SCHIFFER, 2006, p. 5)

Desde então, o município passou a ser responsável por aplicar os instrumentos de gestão urbana que deveria visar o ordenamento territorial de forma justa e democrática. Essa aproximação das políticas de gestão urbana com as especificidades locais é relevante, na medida que, cada município possui características e necessidades distintas. Entretanto, mostra-se necessário analisar se as ações das gestões municipais estão efetivamente voltadas para os interesses coletivos de busca por cidades mais justas ou se estão ligadas à interesses de grupos hegemônicos que disputam a produção do espaço urbano, como bem colocado por Côrrea (1989).

O Estatuto da Cidade, lei 10.257/2001, foi criado para regulamentar os artigos 182 e 183 da Constituição Federal do Brasil de 1988, estabelecendo um conjunto de diretrizes que regem a política urbana em escala nacional e local. Essas diretrizes estão pautadas nos interesses coletivos, na segurança e no bem-estar de todos os cidadãos, o que indica que a problemática da política urbana não se dá na legislação e sim na falta de aplicabilidade dos instrumentos propostos (GOULART et al., 2014). O Estatuto,

[...] rege as questões da ordenação do território e da participação comunitária, objetiva, no seu bojo, promover a inclusão social. Estabelece, também, as regras referentes: ao uso e a ocupação do solo urbano e ao controle da expansão do território urbano e propõe a definição da função social da cidade e da propriedade, especificada no Plano Diretor Participativo. (BAZOLLI, 2007, p. 72)

O Estatuto não resolve e nem elimina como um todo os conflitos urbanos relacionados à apropriação espacial pelo capital e pelo o uso e o direito a cidade, porém os retira da sombra, mostrando que são problemas sócio-espaciais que devem ser resolvidos a partir de um conjunto de instrumentos e ações públicas (RODRIGUES, 2004). Ele reafirmou a necessidade de um planejamento urbano democrático, onde as suas políticas sejam voltadas as reais necessidades das sociedades buscando uma gestão mais democrática e participativa. Portanto, um dos principais ganhos é a obrigatoriedade da participação popular nas propostas de ordenação do território. Reafirmou, também, a função social da propriedade que está relacionada com o uso adequado do lote pautado nos múltiplos interesses da coletividade, o que nem sempre coincide com o 
interesse do proprietário particular (THOMÉ, 2017). O cumprimento desta função está prevista desde a Constituição de 1934, porém só com o Estatuto da Cidade em 2001 ao caracterizar no artigo $2^{\circ}$ do Capitulo I quais as diretrizes gerais para que ocorra o pleno desenvolvimento da função social da propriedade, é que de fato se tem os parâmetros legais estabelecidos para que uma propriedade realize a função social. O Art. $2^{\circ}$, inciso VI, determina quais as características das propriedades urbanas que não estão se enquadram nos critérios de função social, sendo eles:

a) a utilização inadequada dos imóveis urbanos; b) a proximidade de usos incompatíveis ou inconvenientes; c) o parcelamento do solo, a edificação ou o uso excessivos ou inadequados em relação à infraestrutura urbana; d) a instalação de empreendimentos ou atividades que possam funcionar como polos geradores de tráfego, sem a previsão da infraestrutura correspondente; e) a retenção especulativa de imóvel urbano, que resulte na sua subutilização ou não utilização; f) a deterioração das áreas urbanizadas; g) a poluição e a degradação ambiental (BRASIL, 2001).

Em seu Capítulo II (Dos Instrumentos da Política Pública), estão definidos os instrumentos a serem usados para combater a especulação imobiliária nas cidades. No capítulo, detalha-se a operacionalidade dos instrumentos a serem usados pelo poder público municipal para a ocupação e controle dessas áreas voltadas para a especulação imobiliária. Na seção II do capítulo (Do Parcelamento, Edificação ou Utilização Compulsórios) que compreende os artigos $5^{\circ}$ e $6^{\circ}$ determina o parcelamento, a edificação ou a utilização compulsória para solo urbano não edificado, subutilizado ou não utilizado. Os proprietários dessas terras são notificados pelo poder público municipal para que parcelem, edifiquem ou destinem uma utilidade nãoespeculativa para sua propriedade. Após a notificação ao proprietário, que ocorre de forma pessoal e presencial, o proprietário ao acatar a ordem possui um ano para elaborar um projeto de utilização de sua propriedade.

Na seção III (Do IPTU Progressivo no Tempo), que compreende o artigo $7^{\circ}$, prevê a aplicação do Imposto Predial e Territorial Urbana no tempo caso os prazos estabelecidos no artigo $5^{\circ}$ do Estatuto não sejam cumpridos pelos proprietários notificados. O IPTU Progressivo no tempo caracteriza-se pelo aumento do percentual de impostos sobre essa terra não edificada, subutilizada ou não utilizada durante cinco anos. $\mathrm{O}$ aumento dessa taxa não pode exceder duas vezes o valor do ano anterior, respeitando a alíquota máxima de quinze por cento. Caso a obrigação de parcelar, edificar ou utilizar não seja atendida, o poder público municipal manterá a cobrança na alíquota máxima por no máximo 5 anos.

Por fim, na seção IV, Da Desapropriação com Pagamentos em Títulos, que compreende o artigo $8^{\circ}$, o Poder público municipal poderá proceder à desapropriação caso o proprietário não tenha cumprido o parcelamento, edificação ou uso do solo urbano nos cinco anos em que o IPTU Progressivo no Tempo foi aplicado. O pagamento pela desapropriação se dará por títulos da dívida pública e o valor a ser pago não computa expectativas de ganhos com lucros cessantes e juros compensatórios.

Um dos problemas apontados por Silva (2006) é o fato de que essas terras que não cumprem a função social da propriedade urbana podem ficar até oito anos sem cumprir sua função de forma legal, tempo esse estabelecido pelo Estatuto da Cidade para que seja cumprido toda a burocracia para a aplicação dos instrumentos. Tal período se dá pela soma de um ano para a apresentação de um projeto, dois anos para iniciar sua execução e cinco anos para de IPTU progressivo, podendo ainda sofrer alterações com a mudança na administração do poder público municipal.

O Plano Diretor é o principal instrumento de gestão urbana na escala municipal que visa à organização territorial quanto aos processos de desenvolvimento e expansão urbana das cidades, em relação aos instrumentos listados anteriormente, o Plano Diretor será a base legal na qual esses instrumentos serão detalhados nos municípios. Na história das cidades brasileiras, os municípios com planos diretores aprovados antes do Estatuto da Cidade não adotavam políticas efetivas de ordenamento territorial, o que ocasionou um crescimento desordenado em algumas cidades brasileiras que refletem nas relações sócio-espaciais até os dias atuais.

Antes do Estatuto da Cidade, já existia a obrigatoriedade da elaboração de Planos Diretores, porém não havia nenhuma punição para os municípios que não elaboravam seus planos. Braga (1995) coloca que

A atual obrigatoriedade da elaboração de planos diretores municipais, imposta pela Constituição Federal de 1988 (artigo 182), não é novidade para os municípios paulistas. Já em 1967, a então Lei Orgânica dos Municípios (Lei n. 9.842/67, posteriormente alterada pelo Decreto Lei Complementar n. 09 de 31 de dezembro de 1969) determinava a obrigatoriedade da elaboração do plano diretor (então denominado plano diretor de desenvolvimento integrado, o chamado de PDDI) a todos os municípios paulistas, e mais 
ainda, estabelecendo como punição aos municípios faltosos, a proibição de auxílio financeiro pelo Estado (BRAGA, 1995, p. 15)

Devido ao caráter tecnocrático que os Planos possuíam, os documentos criados não condiziam com a realidade e possibilidades locais, pois eram delegados para empresas privadas terceiras, a elaboração do documento (BRAGA, 1995). Por isso, é comum encontrar planos que não foram postos em práticas, pois sem a participação popular e sem a presença de técnicos do poder público local sua aplicabilidade torna inviável. Partindo desse deficitário planejamento urbano público das cidades brasileiras, destaca-se a importância do Plano Diretor com a participação popular que visará ordenar o território de forma justa, o Art. 40 que determina sobre o Plano Diretor, explicita que:

Art. 40. O plano diretor, aprovado por lei municipal, é o instrumento básico da política de desenvolvimento e expansão urbana. $\S 1^{\circ} \mathrm{O}$ plano diretor é parte integrante do processo de planejamento municipal, devendo o plano plurianual, as diretrizes orçamentárias e o orçamento anual incorporar as diretrizes e as prioridades nele contidas. $\S 2^{\mathrm{O}} \mathrm{O}$ plano diretor deverá englobar o território do Município como um todo. $\S 3^{\circ}$ A lei que instituir o plano diretor deverá ser revista, pelo menos, a cada dez anos. $\S 4^{\stackrel{0}{ }}$ No processo de elaboração do plano diretor e na fiscalização de sua implementação, os Poderes Legislativo e Executivo municipais garantirão: I - a promoção de audiências públicas e debates com a participação da população e de associações representativas dos vários segmentos da comunidade; II - a publicidade quanto aos documentos e informações produzidos; III - o acesso de qualquer interessado aos documentos e informações produzidos. (BRASIL, 2001)

Nesse sentido, os planos diretores devem estar condicionados aos interesses da população para "planejar democraticamente o futuro da cidade incorporando nessa discussão os diversos agentes sociais, econômicos e políticos que a compõem, buscando compromissos e definindo ações prioritárias." (REZENDE; ULTRAMARI, 2007, p. 265). Após o Estatuto da Cidade, os planos diretores municipais tornaram obrigatórios para cidades com mais de 20 mil habitantes, município em regiões metropolitanas ou aglomerações urbanas, cidades turísticas e cidades com possibilidade de significativo impacto ambiental.

Visando a manutenção da heterogeneidade e pluralidade sócio-territorial proposta pelo Estatuto da Cidade, a Lei de Zoneamento é um instrumento importante caracterizado nos planos diretores municipais onde delimita áreas das quais serão realizadas políticas públicas diferenciadas de acordo com as características de cada uma delas. O zoneamento é o instrumento responsável por determinar o uso do solo urbano nas parcelas delimitadas, tendo como principais objetivos o controle da expansão urbana, a proteção de áreas fragilizadas à ocupação urbana e a atenuação dos conflitos entre uso e atividades (DAINEZI, 2014). O Zoneamento é caracterizado como um procedimento urbanístico que regula o uso do solo em áreas de caráter homogêneos pautado em interesses coletivos, portanto, regula como o espaço urbano será usado.

Entretanto, ao delimitar o zoneamento, deve-se considerar quais os interesses coletivos homogêneos serão priorizados, uma vez que, as políticas públicas podem levar a segregações e exclusões sócio-espaciais. Isso ocorre quando se pauta em interesses de apenas uma parcela da sociedade, na qual seus ideais podem não ser iguais aos diversos grupos sociais presentes nas cidades. Tem-se, portanto, o principal problema do zoneamento, quando realizado de modo tradicional e bem delimitado, pode aprofundar as desigualdades sócio-espacais das cidades e intensificar processos de exclusão, segregação e autosegregação ao delimitar qual tipo de ocupação pode ocorrer na área zoneada. Por isso, é essencial que sejam realizados estudos de caráter técnico-social antes da consolidação de um zoneamento, que vise maior integração entre as parcelas da população independente da renda que estas possuírem.

\section{Aplicação dos instrumentos de ordenamento territorial no município de São Paulo}

O Plano Diretor Estratégico (PDE) do município de São Paulo aprovado em 2014, visa estabelecer os parâmetros para o desenvolvimento e crescimento municipal até 2030 (SÃO PAULO, 2014). As intervenções visam reestruturar o espaço urbano para que o mesmo seja (re)produzido de forma planejada com base nas diretrizes legais e intencionais estabelecidas pela gestão municipal. Como exemplo de reestruturação territorial, a região central é uma das regiões escolhidas para serem realizadas tais intervenções, tendo como objetivo a melhoria e a valorização da região, visando atrair investimentos imobiliários, turísticos e culturais (SÃO PAULO, 2019). O PDE estabelece como princípios norteadores a Função Social da cidade, a Função social da Propriedade Urbana e o Direito à Cidade, bem como a gestão democrática da cidade (SÃO PAULO, 2014), seguindo as diretrizes propostas pelo Estatuto da Cidade (2001) e o Estatuto da Metrópole (2015). 
$\mathrm{O}$ reordenamento territorial proposto pelo PDE possui impactos positivos e negativos na estrutura urbana. As transformações propostas tendem a influenciar a formação dos preços e aluguéis dos imóveis, bem como sua tipologia, diminuindo o tamanho das residências e aumentando o seu preço (LAJUT, 2016). Por outro lado, o Novo Zoneamento aumenta a contrapartida das construtoras imobiliárias para a construção de empreendimentos. Tal questão é pauta atual de disputa em uma arena política entre os agentes hegemônicos e não-hegemônicos, principalmente, pela busca por parte dos agentes imobiliários e pela gestão municipal em isentar social e ambientalmente as construtoras (COLOSSO, 2018).

Retoricamente por parte do poder público municipal e o capital imobiliário, as operações urbanas na cidade destacam-se por ser uma possibilidade de valorização dos aspectos culturais e das potencialidades locais visando à função social da propriedade e da cidade, bem como o direito a mesma, entretanto, como aponta Alves (2011), o planejamento desse espaço é feito como se o mesmo fosse vazio, sem nenhuma forma de vida.

Analisando a função social da propriedade e a aplicação do IPTU Progressivo no município de São Paulo pela ótica jurídica, Santos e Pinto (2019) demonstram que só a partir de 2014 foi que o instrumento passou a ser regulamentado a nível municipal, com a aprovação do PDE. Segundo os autores, no mesmo ano de aprovação do PDE, foram emitidas as primeiras notificações para os imóveis não utilizados, subutilizados e não edificados dando início a uma série de reestruturações territoriais propostas pela gestão municipal.

Em relatório recente divulgado pela Prefeitura de São Paulo, analisando a aplicação dos instrumentos de ordenamento territorial nos imóveis ociosos do município, destacou-se que 1.425 imóveis foram notificados por não cumprirem sua função social. A Tabela 1 apresenta os imóveis ociosos notificados entre 2014 e junho de 2019.

Tabela 1: Imóveis ociosos no município de São Paulo notificados entre 2014 e 2019

\begin{tabular}{lccccccc}
\hline Tipologia/ Ano & $\mathbf{2 0 1 4}$ & $\mathbf{2 0 1 5}$ & $\mathbf{2 0 1 6}$ & $\mathbf{2 0 1 7}$ & $\mathbf{2 0 1 8}$ & $\mathbf{2 0 1 9 *}$ & Total \\
\hline Não utilizado & 38 & 495 & 100 & 20 & 2 & 26 & 681 \\
Não edificado & 35 & 108 & 341 & 18 & 5 & 8 & 515 \\
Subutilizado & 4 & 85 & 108 & 225 & 1 & 6 & 229 \\
Total & 77 & 688 & 549 & 263 & 8 & 40 & 1.425 \\
\hline
\end{tabular}

Fonte: Prefeitura de São Paulo, 2019. *Os dados referentes ao ano de 2019 correspondem até o mês de junho.

Há uma nuance quantitativa entre os anos de 2014 e 2019 em relação a quantidade de imóveis ociosos notificados pela prefeitura no período, o ano de 2018 aparece muito discrepante se comparado com os anos anteriores e até mesmo o ano de 2019 que está contabilizado até o mês de junho. Infere-se que essa diminuição seja decorrência da troca de gestão municipal do ex-Prefeito João Dória (PSDB) para o atual Prefeito Bruno Covas (PSDB), quando o primeiro se candidatou a Governador do estado. A Tabela 2 apresenta a área total dos imóveis ociosos notificados entre 2014 e 2019.

Tabela 2: Área $\left(\mathrm{em} \mathrm{m}^{2}\right)$ dos imóveis ociosos notificados ao ano por tipologia

\begin{tabular}{lrrrrrrr}
\hline Imóvel Ocioso/ Ano & $\mathbf{2 0 1 4}$ & $\mathbf{2 0 1 5}$ & $\mathbf{2 0 1 6}$ & $\mathbf{2 0 1 7}$ & $\mathbf{2 0 1 8}$ & $\mathbf{2 0 1 9} *$ & Total \\
\hline Não utilizado & 12.137 & 248.006 & 117.039 & 81.524 & 501 & 25.522 & 484.739 \\
Não edificado & 190.815 & 721.982 & 478.648 & 129.444 & 5.907 & 4.648 & 1.531 .444 \\
Subutilizado & 4.722 & 628.988 & 203.604 & 27.046 & 3.652 & 33.019 & 901.031 \\
Total & 207.674 & 1.598 .976 & 799.291 & 238.014 & 10.060 & 63.189 & 2.917 .214 \\
\hline
\end{tabular}

Fonte: Prefeitura de São Paulo, 2019. *Os dados referentes ao ano de 2019 correspondem até o mês de junho.

Assim como o observado no número de notificações aos imóveis ociosos, o ano de 2018 apresenta a menor quantidade de área (em metros quadrados) que foi notificada pela gestão municipal. Mesmo assim, até junho de 2019, cerca de 3 milhões de metros quadrados na cidade de São Paulo foram considerados ociosos, considerando que o déficit habitacional da cidade é de aproximadamente de 474 mil moradias (SILVA, 2019), essas áreas notificadas são áreas potenciais para que de fato seja cumprida a função social da propriedade e da cidade, de forma que todos tenham direito à moradia digna e acesso a equipamentos públicos.

A análise espacial das notificações aos imóveis ociosos se deu entre os meses de novembro de 2014 e junho de 2019. Esse recorte temporal do final do ano de 2014 ao meio do ano de 2019, é justificado pela disponibilidade dos dados pela prefeitura municipal e contempla o período de pós-aprovação do Plano 
Diretor Estratégico do município. Do total das 1.425 notificações, foram analisadas 1.294 ações de notificação e monitoramento de forma que fosse possível tecer relações com o que literatura vem apontando sobre a produção do espaço urbano na cidade. As notificações dos imóveis pela gestão municipal foram agregadas nas unidades territoriais das prefeituras regionais como pode ser observado na Tabela 3.

Tabela 3: Notificações de imóveis ociosos por prefeitura regional em São Paulo.

\begin{tabular}{lc}
\hline Prefeitura Regional & Notificações \\
\hline Butantã & 14 \\
Campo limpo & 13 \\
Casa verde-cachoeirinha & 5 \\
Cidade Ademar & 7 \\
Ermelino Matarazzo & 18 \\
Freguesia-Brasilândia & 5 \\
Guaianases & 5 \\
Ipiranga & 194 \\
Itaquera & 3 \\
Jabaquara & 4 \\
Lapa & 64 \\
M'boi mirim & 1 \\
Mooca & 223 \\
Penha & 6 \\
Pinheiros & 1 \\
Pirituba-Jaraguá & 16 \\
Santana-Tucuruvi & 5 \\
Santo amaro & 13 \\
São Mateus & 17 \\
Sapopemba & 1 \\
Sé & 672 \\
Vila Maria - Vila Guilherme & 4 \\
Vila Mariana & 1 \\
Vila Prudente & 294 \\
\hline Total & \\
\hline
\end{tabular}

Fonte: Prefeitura de São Paulo, 2019.

Os resultados encontrados com a sistematização das notificações mostram que, respectivamente, os territórios administrativos das prefeituras regionais da Sé, Mooca, Ipiranga e Lapa são os que concentram o maior número de imóveis notificados pelo governo municipal no período analisado. São áreas que compreende a região central expandida do município, área que por muito tempo não foi de interesse do mercado imobiliário, interessado em outras centralidades econômicas. As Figuras 1 e 2 a seguir apresentam a espacialização das notificações nas prefeituras regionais do município (Figura 1) e de forma mais detalhada nas quadras de cada bairro (Figura 2).

A região da Sé é uma área inicial do processo de ocupação espacial do município desde meados do século XIX (MATOS, 1958; CARLOS, 2007), bem como as regiões da Mooca e Ipiranga são locais de instalação de antigas indústrias (JOSÉ, 2010; SCIFONI, 2013), o que traz indícios importantes para a reflexão de como o capital se apropria e reapropria dos espaços transformando suas formas e funções (SANTOS, 1978) e o papel do componente histórico do território como um elemento da disputa político-territorial.

Na prefeitura regional da Lapa, o distrito da Barra Funda é o que concentra todas as notificações realizadas pelo poder público municipal no período analisado. A Barra Funda se tornou um distrito atrativo para o capital imobiliário que, nos últimos anos, reestrutura o espaço urbano da região com empreendimentos residenciais e comerciais (GAMA, 2008; THOMÉ, 2015).

Na prefeitura regional da Sé, que concentra o maior número de notificações, os imóveis notificados estão presentes em todos os distritos que compõe a subprefeitura, tais como a Consolação, Bela Vista, Liberdade, República, Sé, Bom retiro e Santa Cecília. O distrito de Santa Cecília, nos últimos anos, sofre um processo de gentrificação acentuado, sendo um espaço de disputa por diferentes agentes que reivindicam seu direito de permanência (VITOR et al., 2018). 


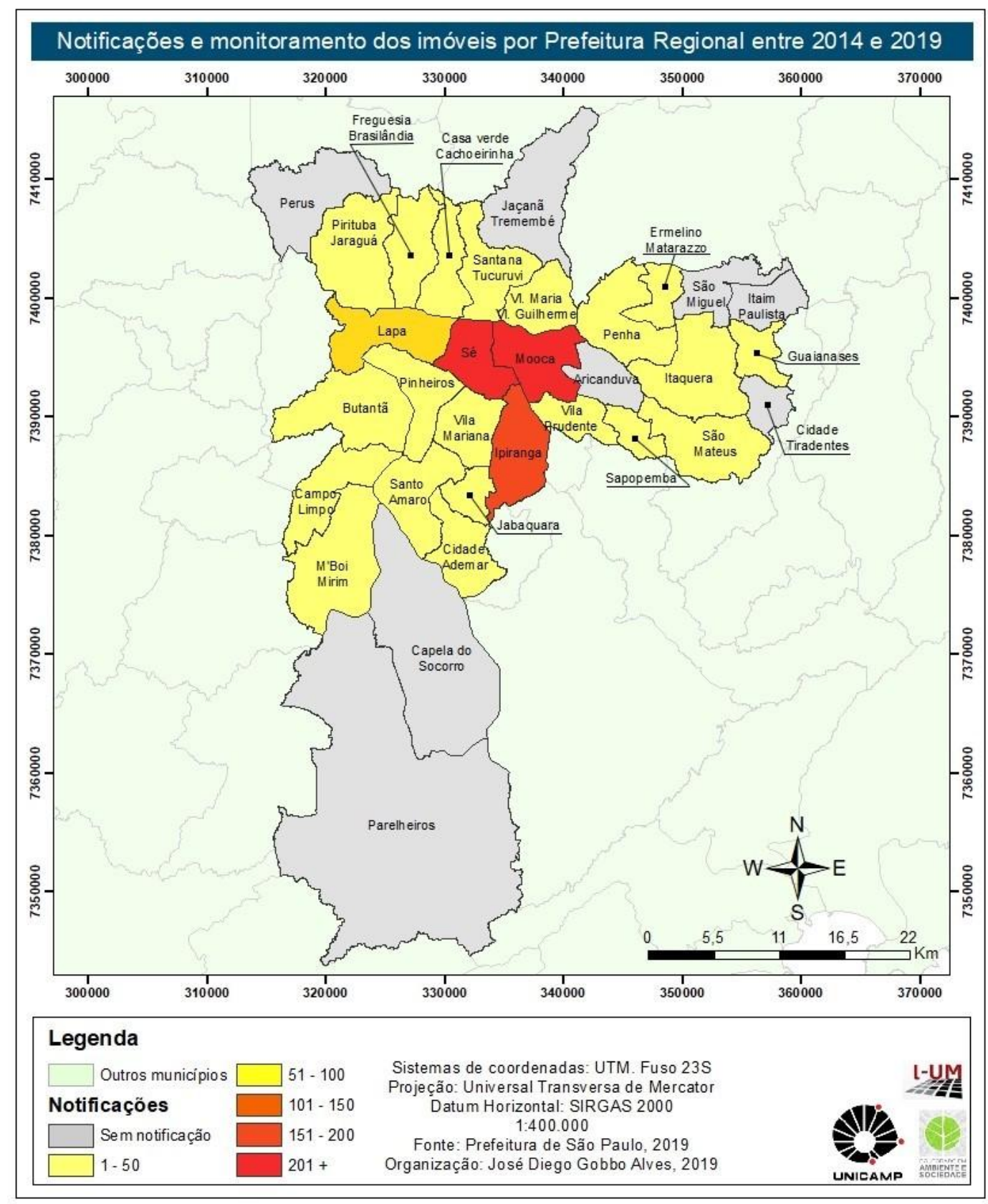

Figura 1: Notificações de imóveis ociosos por prefeitura regional em São Paulo. Fonte: Prefeitura de São Paulo, 2019. Elaborado pelo autor, 2019.

Após a aprovação do Plano Diretor Estratégico em 2002 que estimulou a aplicação de instrumentos urbanísticos, a região da subprefeitura da Sé, bem como toda a região central, voltou a ser um espaço de interesse do mercado imobiliário (RUIVO; FRANCISCO, 2015). Porém, os instrumentos urbanísticos mais aplicados foram àqueles voltados para o adensamento da área central, o que resultou em um aumento da população na área e a permanência de lotes que não cumpriam a função social da propriedade urbana, já que os instrumentos de promoção da função social não foram aplicados (RUIVO; FRANCISCO, 2015). Como exemplo, a lógica da ocupação urbana pautada na segregação e exclusão esteve presente no distrito de Bela Vista, apesar das intervenções pós o PDE de 2002 e tende a ser acentuadas pela ação do mercado imobiliário no distrito, incentivada contraditoriamente pela aplicação dos instrumentos urbanísticos.

Em artigo publicado em 2015, Reina e Comarú indicaram a possibilidade da subprefeitura da Sé ser um espaço atrativo para o mercado imobiliário, destacando o estoque de "territórios em espera", potenciais para a aplicação dos instrumentos urbanísticos. Os dados apresentados aqui confirmaram o que foi esboçado pelos autores, haja vista que a Sé foi a prefeitura regional que possui o maior número de notificações aos proprietários realizadas pelo poder público municipal (Figura 2). 


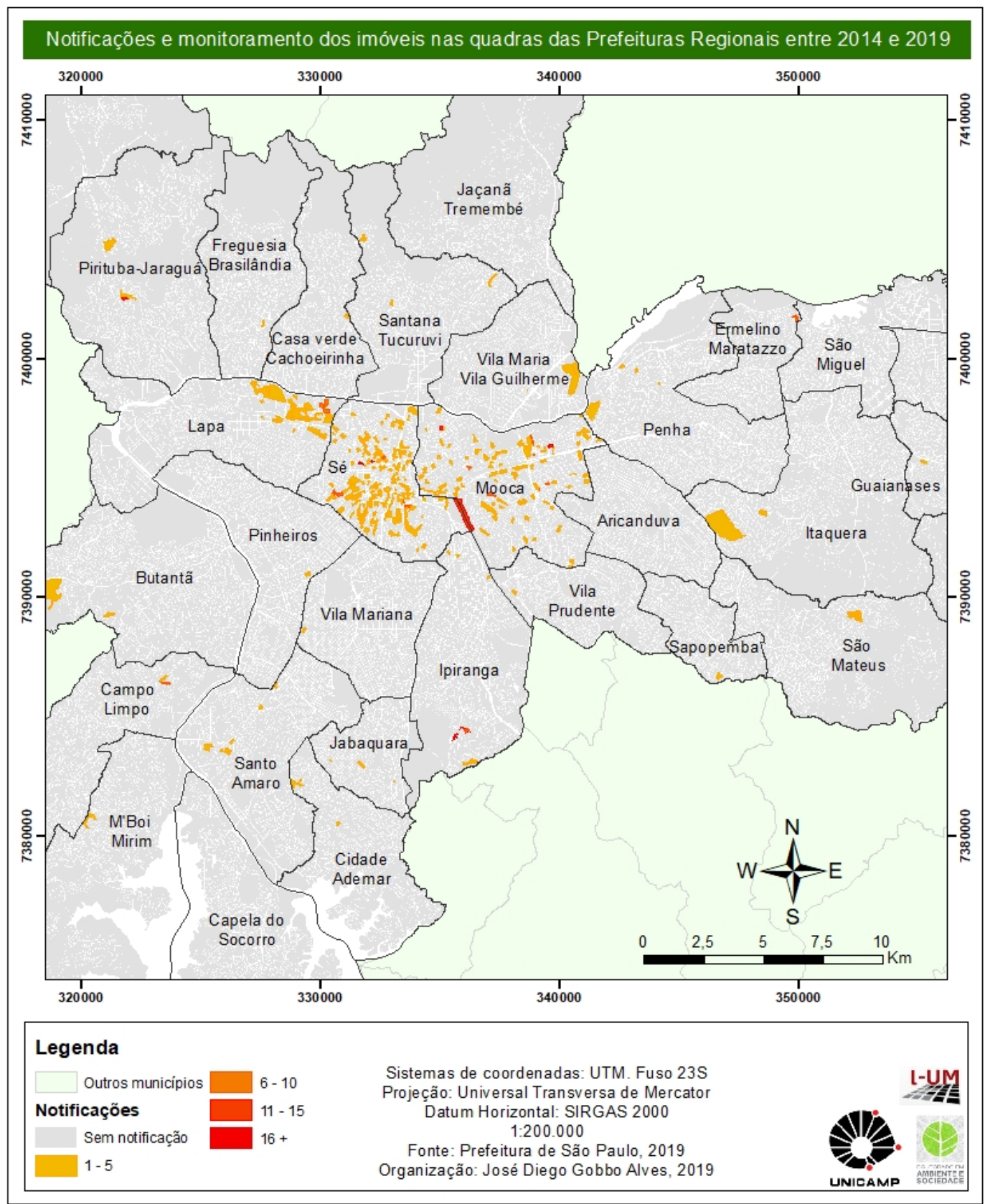

Figura 2: Notificações de imóveis ociosos por quadras em São Paulo. Fonte: Prefeitura de São Paulo, 2019. Elaborado pelo autor, 2019.

Já na prefeitura regional da Mooca, observa-se que o padrão espacial dos imóveis notificados segue às margens da Avenida Celso Garcia, importante eixo estruturador da cidade de São Paulo (Figura 2), o que traz indícios de tendências de desinvestimentos e reinvestimentos na área central, gerando novas centralidades (CARLOS, 2007; REINA; COMARÚ, 2015) e a tendência de formação de um novo perfil socioeconômico da população, acarretando traços de gentrificação na região. O poder público municipal tem um papel colaborativo para essa dinâmica de investimento e desinvestimento e, nem sempre, suas ações visam resolver os problemas sócio-espaciais da população em geral. Em alguns casos, como no Programa Incentivo Seletivo e "Nova Luz", houve um favorecimento explicito de grupos economicamente hegemônicos na revitalização de áreas com urbanidades degradadas (REINA; COMARÚ, 2015). Como colocado por Alves (2011, p. 115).

Com o discurso da requalificação, da limpeza da área dos perigos presentes (especialmente representados pela presença dos usuários de drogas, mendigos, sem teto e população de baixa renda que vive nos cortiços), o poder público, associado à iniciativa privada, consegue, por meio da mídia, apoio de boa parte da população paulistana que desconhece os protestos e a vida existente na localidade. Afinal, os "suspeitos" de atos de violência em geral são trabalhadores do setor formal e informal que trajam roupas simples, com fisionomia muitas vezes cansada. 
Dessa forma, os estudos mostrados aqui apontam para a complexidade que fenômenos urbanos apresentam sendo, neste artigo, referente ao planejamento e ordenamento territorial. O Estatuto da Cidade foi um avanço para a consolidação de um aparato político-jurídico de planejamento territorial, dispondo de um conjunto de instrumentos que possibilitam o Estado, sobretudo no nível municipal, ter maior controle sobre o território, contudo, os resultados apresentados aqui mostram a complexidade e a pertinência dessa discussão atualmente. A aplicação dos instrumentos para ordenar o território da cidade de São Paulo traz fortes indícios sobre a complexidade do uso recente do aparato legal para viabilizar a reprodução do capital no espaço, através de sua reincorporação na dinâmica da acumulação. Tal reincorporação desses territórios na dinâmica do capital demonstra a dimensão espacial da acumulação capitalista que, aliado as políticas urbanas, recriam constantemente novos lugares, centralidades, uso e consumo do território (CARLOS, 2007).

Os territórios que concentram maior número de notificações tornaram interessantes para a dinâmica do capital imobiliário que os enxergaram como uma possibilidade para aumentar a margem de lucro em áreas há muito abandonadas pelo poder público municipal. A viabilização desse processo na cidade só está sendo possível através de um conjunto de práticas de convencimento social, utilizando um discurso pautado na necessidade de novas formas e funções modernas, inovadoras e eficientes dos imóveis urbanos como um modo de dar vida à espaços considerados anteriormente opacos pelo capital.

\section{Considerações finais}

O artigo se propôs a discutir a importância da aplicação de instrumentos de ordenamento territorial que coíbem a especulação imobiliária e como eles estão sendo utilizados no município de São Paulo, especificamente, o Parcelamento, Edificação ou Utilização Compulsórios (PEUC) e o Imposto sobre a Propriedade Predial e Territorial Urbana (IPTU) progressivo no período de 2014 e 2019. No período analisado, foram realizadas 1.425 notificações pelo poder público municipal para proprietários de imóveis dos quais considerou-se que não cumpriam a função social da propriedade urbana ao estarem ociosos na estrutura da cidade.

As questões principais surgida com a análise dessas notificações foram: quais as intencionalidades da aplicação dos instrumentos urbanísticos por parte do poder público municipal? Por que há uma concentração em três principais territórios administrativos, isto é, na Sé, Mooca e Ipiranga? Há uma junção de processos contraditórios de requalificação urbana para o social e reprodução do capital imobiliário? Em uma consulta exploratória da literatura, foram encontradas possíveis respostas para esses questionamentos que caminham na caracterização da área central do município de São Paulo como uma área novamente atrativa para investimentos do setor imobiliário e, possivelmente, do setor de serviços com nichos específicos de mercado que tende a dar continuidade no processo de gentrificação observado no município há anos. A complexidade das ações da gestão municipal quanto à aplicação dos instrumentos de ordenamento territorial demonstra as contradições no uso do aparato jurídico brasileiro para a promoção de cidades socialmente mais justas. Buscou-se argumentar sobre as contradições na aplicação dos instrumentos visando à função social da propriedade e da cidade, que implicaram em diversas consequências para o conjunto social quando sua aplicação é voltada ao mercado imobiliário.

A dificuldade em trazer proposições mais diretas sobre a relação entre a dinâmica do mercado imobiliário e a aplicação dos instrumentos urbanísticos se dá pelo processo em curso, inconcluso, sobre a (re) incorporação desses espaços na dinâmica imobiliária. A interpretação dessas ações fica comprometida pela imprevisibilidade do caminho que essa política percorrerá, mas serve de base temporal para análises futuras das transformações sociais, econômicas e espaciais resultante desse processo analisado.

Deve ser reforçado que os instrumentos de ordenamento territorial, sobretudo no que se refere à função social da propriedade urbana e da cidade, são fundamentais para a promoção de cidades socialmente mais justas. A crítica deste trabalho está pautada na complexidade da apropriação e aplicação desses instrumentos em prol do mercado imobiliário. Nesse sentido, para além da eficácia do instrumento, fez-se um primeiro movimento de interpretação da complexa atuação da gestão municipal de São Paulo quanto à apropriação e aplicação de instrumentos de ordenamento territorial que expressam as intencionalidades do Estado. Estudos de caso nos distritos do município estão sendo desenvolvidas continuamente acerca das dinâmicas do mercado imobiliário, como bem mostrado aqui, e devem ser continuadas juntos aos diálogos propostos neste texto para discutir de forma qualitativa esse primeiro movimento de caráter mais quantitativo-espacial de inferência sobre a complexidade entre política pública urbana e capital imobiliário. 
Notas

A discussão teórica sobre os instrumentos de ordenamento territorial foi iniciada no trabalho de monografia do autor, na qual foi aprofundada para este trabalho e relacionada com a aplicação de tais instrumentos no município de São Paulo. Para mais informações sobre o trabalho, consultar Alves (2016) nas referências bibliográficas.

\section{Referências bibliográficas}

ALVES, G. A. A requalificação do centro de São Paulo. Estudos Avançados, São Paulo, v. 25, n. 71, p. 109-118, abril, 2011.

ALVES, J. D. G. Vazios urbanos na cidade de Piracicaba - São Paulo: Caracterização e análise de sua evolução recente. Trabalho de monografia. Graduação em Geografia. Universidade Estadual Paulista (UNESP), Rio Claro - São Paulo, 2016.

BAZOLLI, J. A. Os Efeitos dos Vazios Urbanos no Custo de Urbanização da Cidade de Palmas - TO. Dissertação de mestrado. Programa de Pós-Graduação em Ciências do Ambiente. Universidade Federal do Tocantins (UFT), Palmas/TO, 2007.

BRAGA, R. Plano Diretor municipal: três questões para discussão. CADERNO DO DEPARTAMENTO DE PLANEJAMENTO (Faculdade de Ciências e Tecnologia - UNESP), Presidente Prudente, vol 1, n. 1, agosto de 1995, pp. 15-20.

BRASIL. Constituição (1988). Constituição da República Federativa do Brasil. Brasília, DF: Senado Federal: Centro Gráfico, 1988.

BRASIL. Estatuto da Cidade. Lei Federal 10.257. 10 de julho de 2001.

BRASIL. Lei no 13.089, de 12 de janeiro de 2015. Institui o Estatuto da Metrópole, altera a Lei no 10.257, de 10 de julho de 2001, e dá outras providências. Diário Oficial da União, Brasília, 2015.

BRASIL. Política Nacional de Mobilidade Urbana. Lei No 12.587. Brasília, 2012.

CARLOS, A. F. A. O Espaço Urbano: Novos Escritos sobre a Cidade. São Paulo: FFLCH, 2007, 123p

COLOSSO, P. São Paulo: o novo ataque dos especuladores. 2018 Disponível em: https://outraspalavras.net/mercadovsdemocracia/o-novo-ataque-dos-especuladores/. Acessado em: 20/10/2019.

CORRÊA, R. L. O Espaço Urbano. Editora ática S.A. São Paulo, 1989.

COUTO, L. Capital, crise e produção do espaço: As determinações críticas da construção habitacional em São Paulo. Revista Do Departamento De Geografia, 29, 279-304. 2015. doi.org/10.11606/rdg.v29i0.102094

DAINEZI, P. M. Análise dos processos e instrumentos de ordenação do território: comparação entre Brasil e Portugal. 2014. 168 f. Tese de doutorado. Programa de Pós-Graduação em Geografia. Universidade Estadual Paulista (UNESP), Rio Claro, 2014.

GAMA, R. Barra Funda em transformação. O Estado de São Paulo, 24 de fevereiro de 2008.

GOULART, J.O.; TERCI, E.T.; OTERO, E. V. Expansão Urbana em cidades médias do interior paulista: entre o estatuto da cidade e o empresariamento. Anais: XIII SEMINÁRIO INTERNACIONAL RED IBEROAMERICANA DE INVESTIGADORES SOBRE GLOBALIZACIÓN Y TERRITÓRIO. SALVADOR, 2014.

HARVEY, D. O Novo Imperialismo. 2. ed. São Paulo: Loyola, 2005. 
JOSÉ, A. B. O processo de desindustrialização no bairro do Ipiranga e suas consequências sócioespaciais. Dissertação de Mestrado. Programa de Pós-Graduação em Geografia Humana. Faculdade de Filosofia, Letras e Ciências Humanas. Universidade de São Paulo (USP), São Paulo, 2010.

MARICATO, E. Para entender a crise urbana. 1. Ed. São Paulo: Expresso Popular, 2015.

MATOS, O. N. São Paulo no século XIX. In: AZEVEDO, A. (org). A cidade de São Paulo: Estudos de geografia urbana. ed: Companhia Editora Nacional, São Paulo, 1958.

LAJUT, J. Análise do impacto do novo Plano Diretor Estratégico da cidade de São Paulo no planejamento de produtos residenciais. Programa de Pós-Graduação em Ciências. Dissertação de mestrado. Universidade de São Paulo (USP), São Paulo, 2016.

LIMONAD, E. Urbanização dispersa mais uma forma de expansão urbana? Formação (Presidente Prudente), v. 1, p. 31-45, 2007.

OJIMA, R; MARANDOLA JR., E. "Apresentação", p. 11-14. In: Ojima, Ricardo; Marandola Jr., Eduardo. Dispersão Urbana e Mobilidade Populacional. São Paulo: Blucher, 2016.

PEREIRA, I. M.; SANTORO, P. F.; MENDONCA, P. H. R.; ROLNIK, Raquel. São Paulo e os territórios do Complexo Imobiliário-Financeiro. In: Cidade Estado Capital: reorganização urbana e resistências em Belo Horizonte, Fortaleza e São Paulo.1 ed.São Paulo: FAUUSP, 2018, v.1, p. 206-221.

REINA, M. L.; COMARÚ; F. A. Dinâmicas imobiliárias e políticas urbanas no centro de São Paulo: uma discussão sobre gentrificação na Mooca. Cad. Metrop., São Paulo, v. 17, n. 34, pp. 419-440, nov 2015. doi.org/10.1590/2236-9996.2015-3406

REZENDE, D. A.; ULTRAMARI, C. Plano diretor e planejamento estratégico municipal: introdução teórico-conceitual. Rev. Adm. Pública, Rio de Janeiro, v. 41, n. 2, p. 255-271, Apr. 2007. dx.doi.org/10.1590/S0034-76122007000200005

RODRIGUES, A. M. Estatuto da Cidade: função social da cidade e da propriedade. Alguns aspectos sobre população urbana e espaço. CADERNOS METRÓPOLE, N. 12, pp. 9-25. 2004.

ROLNIK, R.; KLINK, J. J. Crescimento econômico e desenvolvimento urbano: por que nossas cidades continuam tão precárias? Novos Estudos. CEBRAP, p. 89-109, 2011. dx.doi.org/10.1590/S010133002011000100006

SANTOS, L. P.; PINTO, F. C. S. O IPTU progressivo como instrumento de política urbana: análise dos dados elaborados no município de São Paulo. Revista Direito Público, v. 15, n. 87, 2019.

SANTOS, M. Contribuição ao estudo dos centros de cidades: o exemplo da cidade de Salvador. São Paulo, 1989.

SANTOS, M. Por uma Geografia Nova. São Paulo: Hucitec, Edusp, 1978.

SÃO PAULO. Lei $\mathbf{n}^{\mathbf{0}} \mathbf{1 6 . 0 5 0 / 2 0 1 4}$. Institui o Plano Diretor Estratégico do Município de São Paulo. São Paulo, 2014.

SÃO PAUlO. Plano Estratégico: 5 anos da Lei $\mathbf{n}^{\mathbf{0}} \mathbf{1 6 . 0 5 0 / 2 0 1 4}$. Disponível em: https://gestaourbana.prefeitura.sp.gov.br/wp-content/uploads/2019/09/Balanço-de-5-anos-do-PDE20190911-2.pdf. Acessado em: 09/11/2019.

SERAFIM, M. P; DIAS, R. Análise de política: uma revisão da literatura. Cadernos Gestão Social, v. 3, n. 1, p. 121-134, 2012.

SILVA, E. São Paulo tem déficit de 474 mil moradias, diz estudo. Disponível em: https://www1.folha.uol.com.br/cotidiano/2019/09/sao-paulo-tem-deficit-de-474-mil-moradias-dizestudo.shtml . Acessado em: 10/11/2019. 
SILVA, M. L. A função social da propriedade segundo o Estatuto da Cidade: A necessidade de uma interpretação crítica e extensiva. 2006 Disponível em: https://jus.com.br/artigos/13028/a-funcao-social-dapropriedade-no-estatuto-da-cidade. Acessado em: 09/11/2019.

SCHINFFER, S. R. Novos instrumentos de gestão urbana: entre transformações socioeconômicas e a participação de organizações sociais. Anais Nuevas Dimensiones de la Industria y de lo Urbano en las Metrópolis Latinoamericanas, 2006.

SCIFONI, S. Lugares de memória operária na Metrópole paulistana. GEOUSP - espaço e tempo, São Paulo, N³3, pp. 98- 110, 2013. doi.org/10.11606/issn.2179-0892.geousp.2013.74304

SOUZA, M. L. ABC do Desenvolvimento Urbano. Bertrand Brasil, Rio de Janeiro, 2013.

SPOSITO, M. E. B. A produção do espaço urbano: escalas, diferenças e desigualdades socioespaciais. In: CARLOS, Ana Fani A.; SOUZA, Marcelo Lopes de; SPOSITO, Maria Encarnação Beltrão (orgs.). A produção do espaço urbano: agentes, processos, escalas e desafios. São Paulo; Contexto, 2011. p.123-145.

THOMÉ, C. (Des)ocupação de imóveis em centros urbanos e seu impacto no acesso à moradia digna. Cadernos Jurídicos, São Paulo, ano 18, nº 46, p. 57-76, Janeiro-Março/2017.

VILLAÇA, F. O que todo Cidadão precisa saber sobre Habitação. Global Editora. São Paulo. 1986.

VITOR, C; et al. Resistências e conflitos marcam a gentrificação em São Paulo. Disponível em: https://paineira.usp.br/aun/index.php/2018/02/07/resistencias-e-conflitos-marcam-a-gentrificacao-em-saopaulo/ . Acessado em: 07/11/2019.

(1) (요 (2)

Este artigo é distribuído nos termos e condições do Creative Commons Attributions/AtribuiçãoNãoComercial-CompartilhaIgual (CC BY-NC-SA). 